\title{
Representing Chinese Malaysians Culture in the Street Food Through the Chinese-English Translation Techniques
}

\section{Hongxiang Zhu, Lay Hoon Ang, Sabariah Md Rashid, Nor Shahila Mansor}

To Link this Article: http://dx.doi.org/10.6007/IJARBSS/v11-i4/9838

DOI:10.6007/IJARBSS/v11-i4/9838

Received: 17 February 2021, Revised: 20 March 2021, Accepted: 12 April 2021

Published Online: 30 April 2021

In-Text Citation: (Zhu et al., 2021)

To Cite this Article: Zhu, H., Ang, L. H., Rashid, S. M., \& Mansor, N. S. (2021). Representing Chinese Malaysians Culture in the Street Food Through the Chinese-English Translation Techniques. International Journal of Academic Research in Business and Social Sciences, 11(4), 1395-1407.

\section{Copyright: (c) 2021 The Author(s)}

Published by Human Resource Management Academic Research Society (www.hrmars.com)

This article is published under the Creative Commons Attribution (CC BY 4.0) license. Anyone may reproduce, distribute, translate and create derivative works of this article (for both commercial and non-commercial purposes), subject to full attribution to the original publication and authors. The full terms of this license may be seen at: http://creativecommons.org/licences/by/4.0/legalcode

Vol. 11, No. 4, 2021, Pg. 1395 - 1407

Full Terms \& Conditions of access and use can be found at http://hrmars.com/index.php/pages/detail/publication-ethics 


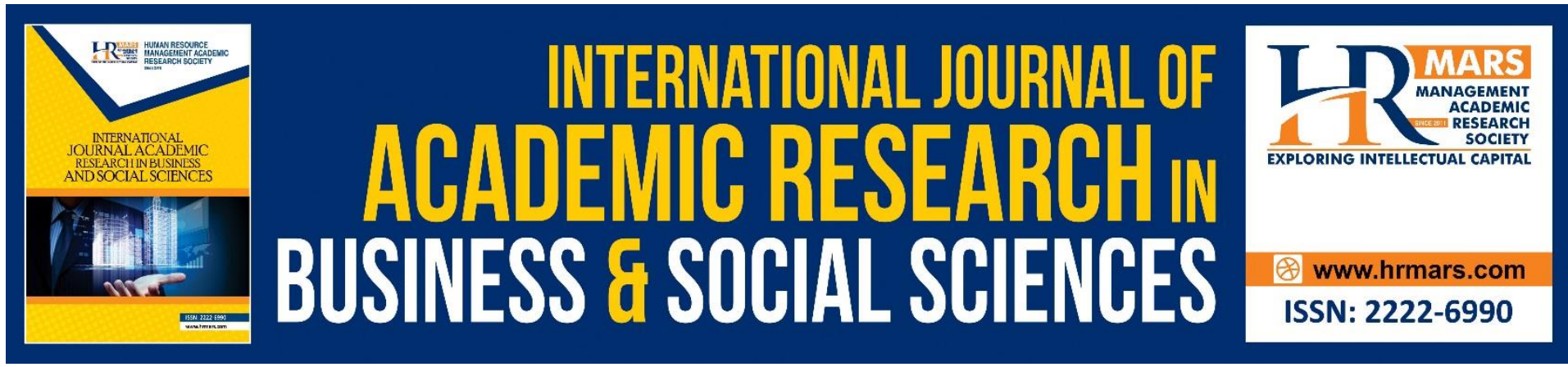

\title{
Representing Chinese Malaysians Culture in the Street Food Through the Chinese-English Translation Techniques
}

\author{
Hongxiang Zhu, Lay Hoon Ang, Sabariah Md Rashid, Nor \\ Shahila Mansor
}

Faculty of Modern Languages and Communication, Universiti Putra Malaysia, Serdang,

Selangor 43400, Malaysia

Email: hlang@upm.edu.my

\begin{abstract}
Street foods refer to the ready-to-eat foods and beverages prepared or sold by vendors or hawkers especially in the streets or hawker centers. Though food-related items are often culture-specific, fewer have discussed the cultural representation behind the translation of street food. This paper aims to identify the prevailing translation techniques used in translating Chinese street food names and to examine how culture is represented through these translation techniques. Penang is selected as the research setting in this qualitative case study. Three types of food - rice dishes, noodle dishes and other staple foods such as dumplings, rice porridge and dim sum are collected. The sample size is 405 street food names in pair of English translation versions. The taxonomy of translation techniques is based on Marco's (2019) translation techniques on food-related items. The results revealed a sourceoriented tendency. It is found that literal translation and transliteration with source linguistic structure, dialect pronunciation and Chinese pinyin preserve source culture. The techniques neutralization and amplification clarify the ingredients, cooking methods of the food, representing a respect to Malaysian local culture. The techniques omission and cultural adaptation bring the food more familiar to English culture, representing the hospitality to the consumers.
\end{abstract}

Keywords: Street Food, Translation Techniques, Cultural Representation, Chinese, Penang

\section{Introduction}

The scholars have recognized the widespread increased interest in food and gastronomy at a global level and the volume of translated food-related texts has been hugely amplified (Chiaro \& Rossato, 2015; Li, 2019; Rossato, 2015). This means that food-related items in translation are getting more and more attention. Yet, despite a rapidly expanding market for translation of food-related texts, the relationship between food, culture and translation remains under-researched (Chiaro \& Rossato, 2015). Therefore, the research territory of this study focuses on food translation and culture. 
Street foods are defined as ready-to-eat foods and beverages prepared and/or sold by vendors or hawkers especially in the streets and other similar places (FAO, 2021). According to Morano et al. (2018), street food is consumed daily by 2.5 billion people worldwide. This reflects the global popularity of street food. Although much street food is an expression of local culture so exhibits great diversity for sale around the world (Cardoso et al., 2014) and Malaysia's Penang is acknowledged as "Asia's Greatest Street Food City" by CNN Travel and declared as "Best Street Food in Asia" by Time Magazine (Cripps, 2017). Little attention is specifically dedicated to the translation of Malaysian street food names with an exception of Zhu and Ang (2020)'s study on translation techniques of street food in Malacca. However, that study did not involve the cultural representation of street food.

Thus, the present study aims to analyze the translation techniques in translating street food names and to examine how the cultures are represented. In this present study, street foods specifically refer to the foods sold by individual vendors or hawkers in the streets or hawker centers and street food here refers to food existed and eaten around Chinese Malaysian society. This study contributes to the food translation by taking street food specifically into consideration and to the cultural studies in view of translation.

\section{Literature Review}

Street foods, also known as hawker foods, provide an essential source of inexpensive ready-to-eat food for workers of every class and occupation (Tinker, 1999). Although street food arrives at a popular level around the world and the amount of street food globally is increasing for the consumers, as Tarulevicz \& Ooi $(2019$, p.3), hawking was a public health issue because of the spread of diseases such as cholera and typhoid. That is why studies regarding the food safety of street food practices (Haque \& Kohda, 2020; Reddy et al., 2020) remain a hot topic. In addition, reviewing the studies concerning street food shows that the attention was also focused on travellers' destination experiences (Yeap et al., 2019). For instance, Yeap et al. (2019) argued that the post-consumption process of Penang street food among the young domestic travellers is rooted in affective states. It can be concluded that little studies on street food were conducted in view of linguistic aspect.

Translation technique is the skill or technique required in the concrete implementation and application of a certain translation method in translation activities (Xiong, 2014). Among previous studies concerning translation of food items, they proposed the taxonomies to account for the translation techniques between source text items and their translated target versions. Reynolds (2016) found that literal translation, transliteration and the addition of an annotation appeared in food translation, but the focus was confined in Taiwanese foods. AlRushaidi \& Ali (2017) proposed a framework for translating food names. These translation techniques are borrowing, literal translation, using a superordinate word, amplification, reduction, translation by cultural substitution and using a load word plus an explanation. However, the focus mentioned in Al-Rushaidi \& Ali's (2017) study was food menus in restaurant restaurants and coffee shops. Graziano (2017) adopted Vinay and Dalbernet's (1958) borrowing, calque, literal translation, transposition, modulation, equivalence or idiomatic translation and adaptation in menus taken from the websites, but these techniques above have been revised and augmented by Newmark (1988). Li (2019) found that translating Chinese food names into English could use intralingual translation, interlingual translation and intersemiotic translation, but the research was from a macro perspective and did not show the specific techniques for food translation. Oster and Molés-Cases (2016) applied intracultural and intercultural adaptation, neutralization, omission, re-creation and literal 
translation to translate food-related culturemes, but the focus was on parallel corpus from literary texts. A discussion was made on the translation techniques of food-related culturespecific items (Marco, 2019), which shed light on this current study by the application of borrowing, literal translation, neutralization, amplification, omission, intracultural adaptation and intercultural adaptation.

Even though there is less one-size-fits-all taxonomy in food translation analysis, Marco's (2019) taxonomy is relatively more comprehensive on food translation. The reasons of adoption in this current study are twofold. Firstly, Marco's (2019) taxonomy contains the techniques of previous studies, thus can revise and update. For example, Marco's (2019) borrowing technique contained Reynolds's (2016) transliteration, as Dong (2021) stated that borrowing technique included natural borrowing (also called transliteration) and direct borrowing. Secondly, some scholars adopted Marco's (2004) taxonomy on food-related translation, such as Oster and Molés-Cases (2016). Through the time of 2004 and 2019 is different, the techniques used in Oster and Molés-Cases's (2016) study are similar with the version of Marco (2019). Besides, Zhu and Ang's (2020) taxonomy on street food translation adopted Marco's (2019) taxonomy. This reflects the applicability of this taxonomy.

\section{Problem Statement}

Translating food items in Malaysia can be a challenging task in two aspects. Firstly, such items are culture-bound as Marco (2019) states that food-related items are often culturespecific and can therefore be regarded as a potential source of translation problems. Rather, translating culture-specific items is difficult viewed from Aixelá (1997) who argued that culture-specific item is a product of the non-existence either of the referred item or of its different intertextual status in the cultural system of the readers of the target text. Thus translating food-related culture-specific items encounters challenges.

Secondly, in the context of Malaysian street food translation, this problem of translation increases due to that the fact that various types of food are offered by the street food vendors. The diverse cultural background of the food in the market might put forward some complexity in translation and cultural representation. According to Al-Rushaidi and Ali (2017), without an awareness of the intricacies involved in the translation process, a translator might unconsciously produce a translation characterized by unintelligibility or inappropriateness. Besides, most of the previous case studies on the translation of menus showed that menu translators were non-professionals who could not fill the cultural gap (Ghafarian et al., 2016). The translation of street food names is normally done by street food vendors who are very likely never go through translation training. The translation could be made base on their way of calling the food or suggestions from the stakeholders around them including the eatery's owner, customers or workers who make the sign board for the food stall. The nonprofessional translation might give rise to the diversified translated food names that confused the consumers.

This study looks into the issue of street food translation with the concern on how the translation of street food are made by the food vendors who are not professional in translation. The translation techniques applied is worth investigating in order to give an insight on street food translation. Furthermore, due to the diversified background of Chinese street food vendors, the translation is found lack of consistency. For example, a popular street food "curry noodle" (noodle in curry broth) is found translated in a few versions with different spelling, such as Curry Mee, Kari Mi, Mee Curry, Kari Mee and Ga Li Mian. Some of these translated names are actually could be traced back to the pronunciation of Chinese standard 
language and also different Chinese dialects. Ga Li Mian is spelled according to the standard Chinese phonetic system Hanyu Pinyin while Kari Mi sounds very close to the Hokkien (one of the dialects in Fujian Province, China, and also a common Chinese dialect in Malaysia) pronunciation. Among the translated names, the variation found does not limit to the translation of "curry" (which are curry, kari, ga li) but also to "noodle" (which are noodle, mee, mi, mian). Therefore, the inconsistently translated names via rather casual manner of mix and match may post confusion which does not help the understanding of consumers who are not from the Chinese language circle, let alone tourists from overseas. At the same time, it raises a question to the hidden cultural representation that lies behind the different spelling of the street food which closely related to general public of Chinese society in Malaysia. The cultural representation of Chinese street food translated names can be regarded as a virgin area that needs to be explored as it may shed lights not only to the translation studies but also to the sociolinguistic studies of grass root community in a multilingual country.

There are two gaps of food translation studies. Firstly, the research data of previous studies were confined in literary translation, restaurant menus or tourism website and street food was ignored in translation studies. This might be because of the lower status of street food from the simple location and environment with healthy issues. However, based on Chiaro \& Rossato (2015), street food has been gentrified and elevated to the realms of haute cuisine. Street food should not be ignored any more. Secondly, most studies on food translation focused on translation techniques since translating food-related culture-specific items is regarded as a difficulty, cultural representation through food translation has yet to appear.

To fill the gaps, a qualitative study is conducted since it tends to explore, understand and describe a translation phenomenon rather than to explain or predict the connections, relations or comparisons. A case study will give insights into food translation and cultural representation. By such knowledge on this issue, it will provide a ground for other applications of cultural issues through translation. Accordingly, the main aims of this study can be stated as follows:

(1) to identify what translation technique prevails in the translation of street food names into English;

(2) to examine how culture is represented through translation techniques.

\section{Methodology}

Qualitative research is functional in exploring uncertain or unknown aspects of a phenomenon and in capturing the essence of the phenomenon (Teddlie \& Tashakkori, 2009). This study falls into this category since it aims to gain a deep insight of translation and cultural issues through street food. The sample of this study is the textual verbal names of street food in pair of the translated English versions. The source text is the Chinese street food name in Chinese language and written in Chinese characters while the target text is the English name written in alphabets and may consist of transliteration and a small mixture of other languages such as Malay language. This study is qualitative in nature though it also uses the numbers to substantiate the results. Besides, the scope of this study is translation technique rather than quality assessment, so that the possible error in translation of street food is not assessed.

The data collection is conducted in Penang, an island state located in the northern region of Malaysia, is known for its mouth-watering street food (Yeap et al., 2019). The actual location of Penang for data collection are Chulia Street, New Lane Hawker Centre, Kimberley Street, Macallum Street Night Market and Red Garden Food Paradise. To collect adequate 
data, this study collects all proper data in each selected setting. Purposive sampling method is used to select samples based on the following criteria: (1) only Chinese street food names with the translated versions are included; some food names, such as Maggie and Curry Noodle, even though originated from Malaysia and India, are also included since these food are also eaten among Chinese Malaysian society and reflect the real cultural livelihood of people; (2) three types of street food (rice dishes, noodle dishes and others based mainly on staple food) are included. 'Others' type of street food refers to other staple food such as dumplings, rice porridge and dim sum; (3) fruit and beverages are not included in this study because fruit and beverages have unique categories with different features.

The data of this fieldwork is collected from September 2020 to October 2020 since this study desires to explore the latest translation phenomenon of street food names in order to offer a novel description for translation issues. Data collection procedures are as followed: (1) first, the researcher identifies the food courts and locations; (2) the researcher walks along every selected area and collects the food names in pair of translation through taking pictures for convenience; (3) the researcher gathers background information of the food and names including source of clans from the stall operators in order to better understand the food; (4) the researcher transcribes the data from pictures to textual form into Excel form.

For the analysis, the following seven consolidated translation techniques was identified mainly based on Marco's (2019) model: borrowing (natural transliteration), literal translation, neutralization, amplification, omission, intracultural adaptation and intercultural adaptation. The extraction of data is based on the definition and scope of each translation technique. For example, 碳烧海鲜炒粿条Tan Shao Hai Xian Chao Guo Tiao and its translation 'Charcoal Seafood Char Koay Teow' show the transliteration with Char Koay Teow whose pronunciation is similar with source dialect Chao Gui Diao and literal translation for Charcoal Seafood whose back translation is similar as Tan Shao Hai Xian. The analysis of translation techniques of this study is based on the above techniques with examples extracted from the collected data of Chinese street food names in Penang, Malaysia.

\section{Findings}

In this study, the analysis is conducted based on collected 405 street food names in pair with their translations. The same street food names in different places are also collected and calculated in numbers. Although there are seven consolidated types of translation techniques, the techniques used in street food names show either the single or combined forms, yielding a total of 20 types of translation techniques identified in actual translation. The actual results are as Table 1: 
Table 1 Distribution of translation techniques of street food names

\begin{tabular}{lll}
\hline Translation technique & Occurrences & Percentage \\
\hline Literal translation + Transliteration & 134 & $33.09 \%$ \\
Literal translation & 96 & $23.70 \%$ \\
Transliteration & 96 & $23.70 \%$ \\
Literal translation + Neutralization & 14 & $3.46 \%$ \\
Literal translation + Omission & 13 & $3.21 \%$ \\
Transliteration + Omission & 10 & $2.47 \%$ \\
Literal translation + Amplification & 9 & $2.22 \%$ \\
Literal translation + Transliteration + Omission & 9 & $2.22 \%$ \\
Transliteration + Amplification & 4 & $0.99 \%$ \\
Literal translation + Amplification + Omission & 4 & $0.99 \%$ \\
Literal translation + Cultural adaptation & 4 & $0.99 \%$ \\
Literal translation + Transliteration + Neutralization & 3 & $0.74 \%$ \\
Neutralization & 2 & $0.49 \%$ \\
Transliteration + Neutralization & 1 & $0.25 \%$ \\
Transliteration + Neutralization + Amplification & 1 & $0.25 \%$ \\
Transliteration + Cultural adaptation & 1 & $0.25 \%$ \\
Literal translation + Cultural adaptation + Omission & 1 & $0.25 \%$ \\
Literal translation + Transliteration + Amplification & 1 & $0.25 \%$ \\
Literal translation + Transliteration + Amplification + Omission & 1 & $0.25 \%$ \\
Literal translation + Transliteration + Neutralization + Omission & 1 & \\
\hline Total No. & 405 & $0.25 \%$ \\
\hline$\quad$ The results of Table 1 show a high percentage & & $100.00 \%$ \\
\hline
\end{tabular}

The results of Table 1 show a high percentage (33.09\%) of literal translation and transliteration, followed by single literal translation (23.70\%) and single transliteration (23.70\%). Since the technique literal translation stays close to the source text by Marco (2019) and transliteration fully presents foreign cultures and maintains source culture practices (Liao, 2015). The high percentage of these two techniques, either single or combined, shows the tendency that the translation inclines to the source culture. The source-oriented translation reflects that it retains the original way of calling the foods which is familiar to the Chinese Malaysian, which creates a source culture friendly living space. From the findings, no examples appear for Marco's (2019) intercultural adaptation, thus the study uses general term - cultural adaptation for convenience. The Chinese pinyin and Malay word are shown in italics.

\section{Discussions}

The results as shown in Table 1 also show the complex translation techniques and indicate the diverse cultural representation. The complexity of translation techniques can be seen from an example of a well-known Penang street food - 炒粿条Chao Guo Tiao. This street food is also the frequent food with 24 times among the whole collected names. The street food炒粿条Chao Guo Tiao is popular among Chinese societies in southeastern countries. Char 
Kway Teow was introduced by the Teochew community from the district of Shantou, China (Chang, 1977). This food in Teochew dialect is pronounced Chao Gui Diao. The historical elements, migration and the multicultural setting result in the complex language of street food in Malaysia. 炒粿条Chao Guo Tiao is translated as 'Char Koay Teow', whose pure transliteration is in accord with the dialect pronunciation Chao Gui Diao of the Chinese characters. There are 19 translations which are treated as 'Char Koay Teow' among the whole 24 times of occurrence. More use of this type of transliteration means that this translation of 'Char Koay Teow' among Chinese Malaysian circle gets large acceptations. Apart from the popularity of 'Char Koay Teow', other three types of translations also exist with varieties either in writing or in techniques such as 'Fried Koay Teow' twice, 'Fried Koey Teow' and 'Char Kuey Teow' once respectively. Especially, 'Fried Koay Teow' and 'Fried Koey Teow' are seemingly the same with both technique transliteration for 粿条Guo Tiao and literal translation for 炒 'Fried', but different in writing. This not only presents that the translation of street food is in a non-standard state but also reflects the inclusiveness of the multicultural society which allows the existence of these four different translation versions. In level of cultural representation, culture-bound street food maintains the source culture with the foreign flavor of the pronunciation Chao Gui Diao retained in the translations. This technique could arouse the readers or consumers to memorize the origins and clans. The combination of two different techniques clarifies the half part of cooking method and keeps the other part of cooking ingredient reflects the half and half cultural representation.

Literal translation refers to the use of word-for-word translation, especially in level of linguistic structure. Literal translation, as Newmark (1988) remarks, would distort the meaning. However, the more frequency of literal translation means that this technique could be widely used and be made sense among Chinese Malaysian society. The reason is partly because of the clear and short names and naming methods of street food which is different from restaurant food with large amount of ornaments. For example, 炒饭Chao Fan is mostly eaten by Chinese Malaysian, which is translated literally as 'fried rice'. More use of literal translation signifies that the translation naturally transfers the meaning of the food names and represents the simple pursuit of eating culture of Chinese Malaysian.

Transliteration is a technique which is translated by the corresponding sound of source language, which is also referred to phonetic translation (Liang, 2016). There are three types of transliteration, one is based on the dialect pronunciation of the Chinese characters and the second is based on Chinese Pinyin and the last one is the combination. Some examples of transliteration are given in Table 2.

Table 2 Examples of technique transliteration

\begin{tabular}{llll}
\hline Chinese name & English translation & Phonetic translation & Three types \\
\hline 炒粿条 & Char Koay Teow & Chao Guo Tiao & Regional dialect-based \\
小笼包 & Xiao Long Bao & Xiao Long Bao & Chinese pinyin-based \\
鸿图面 & Hong Du Mee & Hong Tu Mian & Combination \\
\hline
\end{tabular}

The interesting point for transliteration lies in that transliteration shows foreignness or exotic flavor (Shuttleworth \& Cowie, 2014). The pure transliteration based on dialect pronunciation such as 'Char Koay Teow' evokes the clans or origins of the street food, thus this transliteration has become a signal to show their own cultural elements. Chinese Pinyin is designed during the mid-1950s and promulgated in 1958 by the government of the People's Republic of China (Chen, 1999). Transliteration and pronunciation often reflect the regional 
English traditions as well as the original Mandarin (Zhou, 2018). While dialect-based transliteration could represent the regional colors, Chinese pinyin such as Xiao Long Bao represents the national symbol, which illustrates the Chinese invention. Behind the pinyinbased and dialect-based transliteration is the cultural communications between the regional and national variation and between Chinese and English sound systems. Transliteration shows the foreignness and represents the attitude towards the retention of own cultures, both in level of the regional and the national.

Neutralization consists of three forms of replacements: description to explain, generalization and particularization to replace with the more general or more particular item (Marco, 2019). The technique particularization takes up the highest percentage among these three forms of neutralization. The representative example of particularization is 'Pork' which is translated from 肉Rou 'Meat':

Table 3 Examples of translation of 肉Rou

\begin{tabular}{ll}
\hline Chinese name & English translation \\
\hline 肉碎米线 & Pork Mee Sua \\
卤肉饭 & Braised Pork Rice \\
肉碎果条汤 & Minced Pork Koay Teow Soup \\
烧肉 & Roasted Pork \\
肉粥 & Pork Porridge \\
烧肉饭 & Roast Pork Rice \\
烧肉饭 & Roasted Pork Rice \\
烧肉福建虾面 & Yummy Hokkien Prawn Mee \\
招牌全肉煎饺 & Fried Dumplings \\
四代祖传老招牌卤肉 & 4th generation Famous Loh Bak since 1970 \\
汕头砂保肉骨茶 & Claypot Bak Kut Teh \\
来来肉骨茶 & Lai Lai Bak Kut Teh \\
叉烧肉 & Roasted Meat Rice \\
肉粥 & Meat Porridge \\
肉碎云吞面 & Minced Meat Wan Tan Mee \\
肉粥 & Meat Porridge \\
\hline
\end{tabular}

From Table 3 (bold for translation of 肉), among 16 occurrences of 肉Rou, apart from 2 omission, 3 Hokkien dialect ' $B a k^{\prime}$ ' and 4 literal translation to 'meat', 7 translations are treated with a particularization word 'Pork', which clarifies the real ingredient for consumers. Malaysia keeps large amount of Islamic people. This could avoid the mistake of eating beliefs between different cultures. According to Baker (1992), being polite can be far more important than being accurate. This technique better considers the local culture and expresses a respect to other culture through particularization translation. The use of literal translation of 'Meat' to Rou, comparing to the particularization, indeed transfers the meaning but risking a rigid culture export in face of cultural conflicts.

Amplification is often used in which a certain amount of information that do not exist in the source text is added in the target text (Marco, 2019). There are 20 occurrences of the use of technique amplification and are used with other techniques as a complement to clarify the meaning. The main focuses of amplification lie in the addition of ingredient, cooking method, taste, brand name, appearance and good name. 
Table 4 Frequency of added elements in translation

\begin{tabular}{llll}
\hline Elements & Number & Examples of names & Added element \\
\hline Ingredient & 9 & 牛腩面- Beef Soup Mee & Soup \\
Cooking method & 4 & 招牌面- Famous Fried Mee & Fried \\
Taste & 4 & 煎生面- Crispy Noodle & Crispy \\
Brand name & 2 & 福建面- Ah Meng Hockien Mee & Ah Meng \\
Good name & 1 & 槟城风味炒面- Famous Flavor Fried Noodle & Famous \\
\hline
\end{tabular}

From Table 4, the ingredient, cooking method and taste are paid more attention to be clarified. Through the preference of the added elements, the unpretentious eating culture of Chinese Malaysian on street food is represented. In order to clarify the basic food information, the translation uses amplification to know what the street food is, how it cooked and what the taste is. The brand name shows the fame of one food and a good brand name can bring about advantages. The addition of brand name reveals that the vendors try to highlight the particularity of the food, which is also an expression of labeling their source culture, especially through the transliteration of the addition of the brand name. Chinese Malaysian also focuses on the addition of the good name in order to express a sense of honor. That is also a culture that people pursue the best wishes and the sense of pride for their own eaten food.

The technique omission refers to remove the traces of source culture specificity from the target text (Marco, 2019). The nomenclature of Chinese Malaysian street food names often includes place name, person name, brand name, good name, cooking method, ingredient and attribute. These elements are deleted with different extent.

Table 5 Frequency of omission in translation

\begin{tabular}{lll}
\hline Elements & Number & Examples \\
\hline Place name & 6 & 槟城Penang (a state of Malaysia), 社尾She Wei (edge of a city) \\
Person name & 5 & $\begin{array}{l}\text { 阿强A Qiang, 阿贵A Gui } \\
\text { Brand name }\end{array}$ \\
$\begin{array}{lll}\text { 古早味Gu Zao Wei (Antique flavor), 小小鸟Xiao Xiao Niao (Small } \\
\text { bird) }\end{array}$ \\
$\begin{array}{l}\text { Good name } \\
\text { Ingredient }\end{array}$ & 6 & 招牌Famous \\
Attribute & 7 & 捞Lao (mix by lifting and turning) \\
\hline
\end{tabular}

From Table 5, place name, person name and brand name are full of cultural elements. The place names show the origin or eating place of the street food. The vendor often uses the person name as the stall name and the name contains ample Chinese naming style and culture. The omission of place names and person names in translation to some extent decreases the source culture, thus the ample culture-bound street foods are transformed into a common street food without the specialty of source color. Brand names and good names are to gain the fame and accumulate the influence of the street food. The omission ignores the vendors' intention on the food consumption. Comparing to the strong culture-bound place name, person name, brand name and good name, the omission of cooking method, ingredient and attribute could not highly influence the culture export but trigger the lost information of the whole street food. However, while the omission loses the traces of the intention of source text, it offers the readability and fluency to target readers, which represents a type of welcome and hospitality of Chinese Malaysian society. 
According to Marco (2019), cultural adaptation refers to that a target culture item is substituted for the source text item. The cultural adaption technique brings the text closer to the target reader. The example is 'Fried Maggie' as Table 6.

Table 6 Examples of technique cultural translation

\begin{tabular}{ll}
\hline Chinese name & English translation \\
\hline 炒金旦面 & Fried Maggi \\
干炒唯一面 & Fried Maggie \\
炒金旦面 & Fried Maggie \\
炒快熟面 & Fried Mee Maggi \\
\hline
\end{tabular}

From Table 6, these noodles are translated to their local Malaysian brand 'Maggie'. The translation loses trace of either Chinese Mian or Chinese Malaysian 'Mee' and exists with English writing form, which is between Chinese and English. However, cultural adaptation, occupying the least amount and existing affiliating to other techniques, reveal that cultural adaptation is not the main form of translating Chinese Malaysian street food names. This reflects that during the translation process Chinese Malaysian tend to preserve their eating habits and culture rather than largely import foreign cultures into their living environment.

\section{Conclusions}

To sum up, two main conclusions are highlighted in accord with two aims of this study. Firstly, Marco's (2019) can be applied in translating street food names. The results showed that with literal translation and transliteration prevail in the translation of Chinese Malaysian street food names. This signifies that translation techniques incline to a source-oriented tendency. The results show similarities and differences to the results of previous studies. Even though Marco's (2019) result is foreign with more percentage of foreign techniques. The difference is that the extent of this foreign color in this study occupies surprisingly high percentage and Marco's (2019) result is relatively average. That difference might be partly due to the recipients of the different texts. Previous studies on literary texts consider the target text readers and readability while the translation of Chinese street food in Malaysia needs to serve multicultural consumers and maintain some cultural specialty.

The second conclusion concerning the culture representation through translation techniques should also be clarified. The source-oriented techniques with literal translation and transliteration preserve more source culture through maintain the linguistic structure and dialect pronunciation and Chinese pinyin. The techniques neutralization and amplification represent a respect to the local culture. The omission and cultural adaptation though with least percentage also reflect the welcome and hospitality of the Chinese Malaysian society. The complex translation techniques also reflect the multiple selections and it should be clarified that Chinese Malaysian adapts to the multicultural environment with different translation varieties. They maintain their own culture not with non-translation which confined themselves in a pure Chinese circle but with a positive attitude and with respect to other cultures. This study explores the translation and cultural representation through the selected five places of Penang, Malaysia, however, there are some differences in each individual place which is valuable to explore. 


\section{References}

Al-Rushaidi, S., \& Ali, H. (2017). Translating Food Menus from English into Arabic: Linguistic and Cultural Dilemmas. Arab World English Journal for Translation and Literary Studies, 1(1), 201-212.

Aixela, J. F. (1997). Culture-Specific Items in Translation. In R. Alvarez and M. C. Vidal (eds.), Translation, Power, Subversion (pp. 52-78). Clevedon: Multilingual Matters.

Baker, M. (1992). In Other Words: A Course book of Translation. London and New York: Routledge.

Cardoso, R. D. C. V., Companion, M., \& Marras, S. R. (2014). Street food: Culture, economy, health and governance. London and New York: Routledge.

Chang, K. C. (1977). Food in Chinese culture: anthropological and historical perspectives. Yale New Haven: University Press.

Chen, P. (1999). Modern Chinese: Its History and Sociolinguistics. Cambridge: Cambridge University Press.

Chiaro, D., \& Rossato, L. (2015). Food and translation, translation and food. The Translator, 21(3), 237-243.

Cripps, K. (2017). George town, Penang: Asia's greatest street food city? CNN. https://edition.cnn.com/travel/article/george-town-penang-greatest-street-food city/index.html.

Dong, L. (2021). Differentiation and classification of translation techniques, translation methods, translation strategies. Journal of Xiangtan University (Philosophy and Social Sciences), (02) 186-189.

Food and Agriculture Organization of the United Nations (FAO). (2021). Food for the cities: Street foods. http://www.fao.org/fcit/food-processing/street-foods/en.

Ghafarian, M., Kafipour, R., \& Soori, A. (2016). Domestication and Foreignisation Strategies in Restaurant Menu Translation. Pertanika Journal of Social Sciences \& Humanities, 24(4), 1417-1429.

Graziano, A. (2017). Marketing food through translation: An analysis of a hundred menus from Lazio. ESP Across Cultures, 14, 99-114.

Haque, I. T., \& Kohda, Y. (2020). Understanding the impact of social determinants of health in street food safety: a qualitative study in Bangladesh. International Journal of Health Promotion and Education, 58(3), 152-162.

Li, S. (2019). A corpus-based multimodal approach to the translation of restaurant menus. Perspectives, 27(1), 1-19.

Liao, R. (2015). Uighur local food in China and its English translation strategy. Advance Journal of Food Science and Technology, 9(1), 76-78.

Liang, W. W. (2016). Translators' behaviors from a sociological perspective-A parallel corpus study of fantasy fiction translation in Taiwan, Babel, 62(1), 39-66.

Marco, J. (2019). The translation of food-related culture-specific items in the Valencian Corpus of Translated Literature (COVALT) corpus: a study of techniques and factors. Perspectives, 27(1), 20-41.

Morano, R. S., Barrichello, A., Jacomossi, R. R., \& D'Acosta-Rivera, J. R. (2018). Street food: factors influencing perception of product quality. RAUSP Management Journal, 53(4), 535-554.

Newmark, P. (1988). A Textbook of Translation. New York and London: Prentice Hall. 
Oster, U., \& Molés-Cases, T. (2016). Eating and drinking seen through translation: A study of foodrelated translation difficulties and techniques in a parallel corpus of literary texts. Across Languages and Cultures, 17(1), 53-75.

Reddy, A. A., Ricart, S., \& Cadman, T. (2020). Driving factors of food safety standards in India: learning from street-food vendors' behaviour and attitude. Food Security, 1-17.

Reynolds, B. L. (2016). Troublesome English translations of Taiwanese dishes. English Today, 32(2), 15.

Rossato, L. (2015). Le grand culinary tour: adaptation and retranslation of a gastronomic journey across languages and food cultures. The Translator, 21(3), 271-295.

Shuttleworth, M., \& Cowie, M. (2014). Dictionary of Translation Studies. New York and London: Routledge.

Tarulevicz, N., \& Ooi, C. S. (2019). Food safety and tourism in Singapore: between microbial Russian roulette and Michelin stars. Tourism Geographies, 1-23.

Teddlie, C., \& Tashakkori, A. (2009). Foundations of mixed methods research: Integrating quantitative and qualitative approaches in the social and behavioral sciences. Los Angeles, CA: Sage.

Tinker, I. (1999). Street foods into the 21st century. Agriculture and human values, 16(3), 327.

Vinay, J. P., \& Dalbernet, J. (1958). Stylistique comparée du français et de l'anglais. Paris: Didier.

Xiong, B. (2014). Conceptual confusion in translation studies: A case study of translation strategies, translation methods and translation techniques. Chinese Translators Journal, (3), 82-88.

Yeap, J. A. L., Ong, K. S. G., Yapp, E. H. T., \& Ooi, S. K. (2019). Hungry for more: understanding young domestic travellers' return for Penang street food. British Food Journal, 122(6), 1935-1952.

Zhou, S. (2018). The T/Daos shall meet: The failure and success of English transliterations of Mandarin Chinese. English Today, 35(1), 1-6.

Zhu, H., \& Ang, L. H. (2020). Translation techniques of street food-related culture-specific items of Malacca. International Journal of Psychosocial Rehabilitation, 24(6), 1085010861. 